九州大学学術情報リポジトリ

Kyushu University Institutional Repository

\title{
Prediction for progression of transverse cracking in CFRP cross-ply laminates using Monte Carlo method
}

Onodera, Sota

Department of Aerospace Engineering, Tohoku University : Graduate Student

Nagumo, Yoshiko

Department of Aerospace Engineering, Tohoku University : Assistant Professor

Okabe, Tomonaga

Department of Aerospace Engineering, Tohoku University : Professor

http://hdl. hand le. net/2324/4403408

出版情報: Advanced Composite Materials. 26 (5)，pp.477-491，2017-05-22. Taylor and Francis バージョン：

権利関係 : 
原 稿 種 類：研 究論 文

題目：モンテカルロ法によるCFRP 直交積層板のトラン スバースクラック進展解析

(Prediction for progression of transverse cracking in CFRP cross-ply laminates using Monte Carlo method)

氏名および会員資格：

小野寺壮太・学生会員 (Sota ONODERA) ${ }^{* 1}$

南雲佳子・正会員 (Yoshiko NAGUMO) ${ }^{* 2}$

岡部朋永・正会員 (Tomonaga OKABE) ${ }^{* 3}$

勤務先および職名:

* 1 *3 東北大学大学院工学研究科航空宇宙工学専攻 (980-8579 宮城県仙台市青葉区荒巻字青葉 6-6-01)

Department of Aerospace Engineering, Tohoku University

*1大学院生 Graduate Student

*2 助教 Assistant Professor

*3 教授 Professor

連絡先：南雲佳子

干 980-8579 宮城県仙台市青葉区荒巻字青葉 6-6-01

東北大学大学院工学研究科航空宇宙工学専攻

TEL：022-795-6932 FAX：022-795-6983

E-mail:nagumo@plum.mech.tohoku.ac.jp

使用ソフト：Microsoft Word 2016

使用機種: Microsoft Windows 7 Professional 


\section{A b s t r a c t}

This study predicted transverse cracking progression in laminates including $90^{\circ}$ plies. The refined stress field (RSF) model, which takes into account thermal residual strain for plies including transverse cracks is formulated, and the energy release rate associated with transverse cracking is calculated using this model. For comparison, the energy release rate based on the continuum damage mechanics (CDM) model is formulated. Next, transverse cracking progression in CFRP cross-ply laminates including $90^{\circ}$ plies is predicted based on both stress and energy criteria using the Monte Carlo method. The results indicated that the RSF model and the CDM model proposed in this study can predict the experiment results for the relationship between transverse crack density and ply strain in $90^{\circ}$ ply. The models presented in this paper can be applied to an arbitrary laminate including $90^{\circ}$ plies. ( $135 \mathrm{w}$ ords )

Key words: CFRP, composite laminate, transverse crack, energy release rate, Monte Carlo method 
Prediction for progression of transuerse cracking in CFRP cross-ply laminatesusing Monte Carlomethod Sota Onodera, Yoshiko Nagumo, and Tomonaga Okabe

\section{I N T R O D U C T I O N}

Recently, fiber-reinforced plastics (FRPs) have been used in aerospace fields where reducing weight is important. Practically, laminates made by stacking unidirectional fiber -reinforced laminae, which have predefined mechanical properties, are commonly used because unidirectional fiber -reinforced plastic is highly anisotropic. Several kinds of laminate exist. For example, cross-ply laminate has fiber angles of $0^{\circ}$ and $90^{\circ}$ to the loading direction, angle-ply laminate has fiber angles of $\pm \theta^{\circ}$ to the loading direction, and quasi-isotropic laminate has isotropic elastic moduli in the plane. To utilize these laminates of arbitrary lay-up configurations, it is essential to determine the fracture process of the laminate. Fiber-reinforced laminate exhibits specific fracture processes, such as transverse cracks (cracks in a direction parallel to the fiber), delamination, and breakage of the fiber. In these fracture processes, transverse cracking occurs in the earliest stage. The initiation of transverse cracking causes stress redistribution, resulting in delamination and breakage of 
the fiber due to stress concentration at the crack tip. Therefore, it is important to clarify the mechanical behavior of laminate, including transverse cracking.

Various studies have focused on laminate including transverse cracks. ${ }^{1)-29)}$ Pagano et al. ${ }^{1}$ formulated an analytical model that predicts the crack-initiation laminate stress of $\left[0 / 90_{n} / 0\right](n=1,2,3,4)$ cross-ply laminates assuming steady-state cracking, which is the condition under which a transverse crack propagates indefinitely under constant thermomechanical loading. They demonstrated that their analytical results can precisely predict the experiment results for crack-initiated laminate stress. They also compared their results with those obtained by McCartney ${ }^{15,16)}$ and Dvorak et al. ${ }^{14)}$

Wang et $a l .^{2}$ calculated the energy release rate using finite-element analysis assuming that effective flaws in the $90^{\circ}$ ply propagate into transverse cracks. Also, they simulated transverse crack density as a function of applied laminate stress using the Monte Carlo method. In their analysis, statistical distributions of effective flaw length and flaw spacing were assumed.

Gudmundson and $\mathrm{Zang}^{7)}$ proposed a sophisticated model that predicts the thermo-elastic properties of a laminate including transverse cracks. In this model, the average 
crack opening displacement of a transverse crack is assumed to be that of an isotropic elastic medium, and the incremental strain of the ply in which the transverse crack is initiated is calculated. They embedded this model into the classical laminate theory, so that the relationship between transverse crack density of laminates with arbitrary lay-up configurations and their mechanical properties could be estimated analytically. The model formulated by Gudmundson and Zang can calculate the average stress distribution in each ply but this model cannot calculate the local stress distribution in each ply. Kobayashi et al. ${ }^{8,}$ 9) derived the energy release rate for transverse cracks using the model formulated by Gudmundson and Zang, and predicted the formation of transverse cracks in quasi-isotropic laminates. Kobayashi et al. also found that the local stress distribution in each ply could not be determined using the model of Gudmundson and Zang, although the average stress distribution in each ply could be derived.

Okabe et al. 11) formulated the continum damage mechanics model for predicting the stiffness reduction of composite laminates including transverse cracks as a function of crack density. This model can predict the stiffness of laminates damaged due to transverse cracks (or 
surface crack) based on only the mechanical properties of a ply and the lay-up configurations. Furthermore, this model can precisely predict the FEA results and experiment results for the elastic moduli of laminates of arbitrary layup configuration (e.g., cross-ply, angle-ply, and quasiisotropic) including transverse cracks. This model can calculate the local stress distribution in a ply including transverse cracking as a function of crack density.

The present study formulates at model for progression of transverse cracking in laminates including $90^{\circ}$ ply. First, the local stress distribution in a ply including transverse cracking is formulated using the refined stress field (RSF) model, which extends the model formulated by Okabe et al. 11) to take into account residual thermal strain. Next, the energy release rate associated with transverse cracking is calculated using the RSF model. For comparison, the energy release rate based on the continuum damage mechanics (CDM) model is formulated. Furthermore, transverse cracking progression in CFRP cross-ply laminates including $90^{\circ}$ plies is predicted based on both stress and energy criteria using the Monte Carlo method. Finally, the crackinitiated laminate stress and the relationship between transverse crack density and ply strain in $90^{\circ}$ ply are calculated using the RSF or the CDM model. The validity 
of these models is estimated by comparing the results obtained from these models to the experimental and analytical results in previous studies. ${ }^{1)}$, 10) The results for cross-ply laminates are calculated in this study; however, the models presented here can be applied to an arbitrary laminate including $90^{\circ}$ plies.

\section{MECHA N I A L M O D L}

\subsection{Local Stress Distribution in a Ply Including}

\section{Transverse Cracking}

Local stress distribution in a ply including transverse cracking was formulated using the RSF model, which extends the model formulated by Okabe et al. ${ }^{11}$ ) to take into account residual thermal strain. When formulating the RSF model, it was assumed that the ply is thin, and that the damage was due mainly to transverse cracks. Based on these assumptions, the bending of the ply and damage due to delamination were ignored. Figure 1 (a) illustrates a ply including transverse cracks. The 1 -axis is parallel to the fiber, and the 2-and 3 -axes are normal to the fiber. Figure 1 (b) illustrates a representative volume element (RVE) including transverse cracking on both sides, which is part of the ply in Fig. 1 (a). It should be noted that the coordinate system differs from that in Fig. 1 (a). The 
coordinates $x, y$ in Fig. 1 (b) correspond to the 3-, 2-axes in Fig. 1 (a), respectively. The transverse crack is assumed to have a tunnel-like crack surface that is symmetrical about the $y$-axis. The transverse crack does not propagate into the neighboring ply. The crack spacing is $2 l$ and the thickness of the ply is $t_{\text {ply }}=2 t$. The ply strain $\varepsilon_{y}^{p}$ along the $y$-axis (or 2-axis) is applied to the RVE (or ply). Due to the symmetric RVE, the region of definition is limited to $0 \leq$ $x \leq t$ and $0 \leq y \leq l$.

A plane strain in the isotropic plane $(x-y$ plane $)$ in Fig. 1 (b) is assumed. The displacements in directions $x$ and $y$ are defined as $u$ and $v$. Considering thermal residual strain, the strain-stress relationship is expressed as

$$
\begin{gathered}
\varepsilon_{x}^{M}=\frac{\partial u^{M}}{\partial x}=\varepsilon_{x}-\alpha_{2} \Delta T=C_{1} \sigma_{x}-C_{2} \sigma_{y} \\
\varepsilon_{y}^{M}=\frac{\partial v^{M}}{\partial y}=\varepsilon_{y}-\alpha_{2} \Delta T=C_{1} \sigma_{y}-C_{2} \sigma_{x} \\
\gamma_{x y}=\frac{\sigma_{x y}}{G_{23}}=\frac{\partial v^{M}}{\partial x}+\frac{\partial u^{M}}{\partial y} \approx \frac{\partial v^{M}}{\partial x} .
\end{gathered}
$$

Constants $C_{1}$ and $C_{2}$ are defined as

$$
\mathrm{C}_{1}=\frac{1-v_{21} v_{12}}{E_{2}}, C_{2}=\frac{v_{23}+v_{21} v_{12}}{E_{2}}
$$

where $\sigma_{x}$ and $\sigma_{y}$ are stresses along the $x$ - and $y$-axes, $\varepsilon_{x}$ and $\varepsilon_{y}$ are strains considering the influence of thermal residual strain along the $x$ - and $y$-axes, $\varepsilon_{x}^{M}$ and $\varepsilon_{y}^{M}$ are strains not including the influence of thermal residual 
strains along the $x$ - and $y$-axes, $u^{M}$ and $v^{M}$ are displacements not including the influence of thermal residual strains along the $x$ - and $y$-axes, $\gamma_{x y}$ is the engineering shear strain in the $x-y$ plane, $\sigma_{x y}$ is the shear stress in the $x-y$ plane, and $\Delta T$ is temperature change $T-$ $T_{s f}$ from the stress free temperature $T_{s f}$ to the testing temperature $T . E_{1}$ is the longitudinal Young's modulus along 1 -axis, $E_{2}$ is the transverse Young's modulus along the 2 -axis, $G_{23}$ is the out-of-plane shear modulus in plane 2-3, $v_{12}$ is in-plane Poisson's ratio in plane $1-2, v_{23}$ is outof-plane Poisson's ratio in plane 2-3, and $\alpha_{2}$ is the transverse thermal expansion coefficient along the 2 -axis. For engineering shear strain $\gamma_{x y}$ in Eq. (3), the gradient in the $y$ direction of displacement $u$ is assumed to be quite small. The relationship between $\varepsilon_{x}^{M}$ and $\varepsilon_{y}^{M}$ is expressed as

$$
\varepsilon_{x}^{M}=a \varepsilon_{y}^{M}
$$

where $a$ is a proportionality constant defined to satisfy the equilibrium equation of stress. From Eqs. (1), (2), and (5), $\sigma_{x}$ and $\sigma_{y}$ are defined as

$$
\begin{gathered}
\sigma_{x}=\frac{a C_{1}+C_{2}}{C_{1}^{2}-C_{2}^{2}} \frac{\partial v^{M}}{\partial y}, \\
\sigma_{y}=\frac{C_{1}+a C_{2}}{C_{1}^{2}-C_{2}^{2}} \frac{\partial v^{M}}{\partial y} .
\end{gathered}
$$

Additionally, using Eq. (3), $\sigma_{x y}$ is expressed by 


$$
\sigma_{x y}=G_{23} \frac{\partial v^{M}}{\partial x} .
$$

The equilibrium equation of stress is expressed as

$$
\begin{aligned}
& \frac{\partial \sigma_{x}}{\partial x}+\frac{\partial \sigma_{x y}}{\partial y}=0 \\
& \frac{\partial \sigma_{x y}}{\partial x}+\frac{\partial \sigma_{y}}{\partial y}=0 .
\end{aligned}
$$

When $\partial^{2} v^{M} / \partial x \partial y \neq 0$ is postulated and Eqs. (6)-(8) are substituted into Eqs. (9) and (10), the proportionality constant $a$ and the Laplace equation for displacement $v^{M}$ are obtained as

$$
\begin{gathered}
a=-\left\{C_{2}+G_{23}\left(C_{1}^{2}-C_{2}^{2}\right)\right\} / C_{1} \\
\frac{\partial^{2} v^{M}}{\partial x^{2}}+\lambda^{2} \frac{\partial^{2} v^{M}}{\partial y^{2}}=0 ; \lambda=\sqrt{\frac{C_{1}+a C_{2}}{G_{23}\left(C_{1}^{2}-C_{2}^{2}\right)}} .
\end{gathered}
$$

To determine displacement $v^{M}$, the boundary conditions of the Laplace equation in Eq. (12) are given by

$$
\begin{gathered}
v^{M}=0 \quad \text { on } y=0, \\
\frac{\partial v^{M}}{\partial y}=0 \text { on } y=l, \\
\frac{\partial v^{M}}{\partial x}=0 \text { on } x=0, \\
v^{M}=\left\{\varepsilon_{y}^{p}+\left(\alpha_{c}-\alpha_{2}\right) \Delta T\right\} y \text { on } x=t,
\end{gathered}
$$

where $\alpha_{c}$ is the thermal expansion coefficient of the laminate along the $0^{\circ}$ direction. At $y=0$, no displacement $v$ is considered in Eq. (13). Equation (14) was determined from Eq. (7) considering stress $\sigma_{y}=0$ at the crack surface $(y=l)$. Equation (15) was defined based on Eq. (8), considering shear stress $\sigma_{x y}=0$ on the center line of the ply 
$(x=0)$. Additionally, the displacement distribution presented as Eq. (16) in the interface was assumed according to the previous study. ${ }^{25)}$ Therefore, the neighboring ply is thought to be deformed uniformly by $\varepsilon_{y}^{p}$, regardless of the transverse cracks. Using separation of variables and assigning the boundary conditions presented above to Eq. (12), the solution $v^{M}$ of the Laplace equation that satisfies the boundary conditions in Eqs. (13) to (16) can be expressed as

$$
v^{M}=\frac{8 l}{\pi^{2}}\left(\sum_{n=1}^{\infty} \frac{(-1)^{n+1}}{(2 n-1)^{2}} \frac{\cosh [(2 n-1) \pi \lambda x /(2 l)]}{\cosh [(2 n-1) \pi \lambda t /(2 l)]} \sin \left[\frac{(2 n-1) \pi y}{2 l}\right]\right)\left(\varepsilon_{y}^{p}+\varepsilon_{t h}\right)
$$

where $\varepsilon_{t h}$ denotes $\left(\alpha_{c}-\alpha_{2}\right) \Delta T$. When Eq. (17) is substituted into Eqs. (6)-(8), the local stress distribution in RVE is derived as

$$
\begin{gathered}
\sigma_{x}(x, y)=\frac{4}{\pi} \frac{a C_{1}+C_{2}}{C_{1}^{2}-C_{2}^{2}} f(x, y)\left(\varepsilon_{y}^{p}+\varepsilon_{t h}\right) \\
\sigma_{y}(x, y)=\frac{4}{\pi} \frac{C_{1}+a C_{2}}{C_{1}^{2}-C_{2}^{2}} f(x, y)\left(\varepsilon_{y}^{p}+\varepsilon_{t h}\right) \\
\sigma_{x y}(x, y)=\frac{4}{\pi} G_{23} \lambda g(x, y)\left(\varepsilon_{y}^{p}+\varepsilon_{t h}\right) .
\end{gathered}
$$

In the above equations, the functions $f(x, y)$ and $g(x, y)$ are expressed by

$$
\begin{aligned}
& f(x, y)=\sum_{n=1}^{\infty} \frac{(-1)^{n+1}}{(2 n-1)^{2}} \frac{\cosh [(2 n-1) \pi \lambda x /(2 l)]}{\cosh [(2 n-1) \pi \lambda t /(2 l)]} \cos \left[\frac{(2 n-1) \pi y}{2 l}\right] \\
& g(x, y)=\sum_{n=1}^{\infty} \frac{(-1)^{n+1}}{(2 n-1)^{2}} \frac{\sinh [(2 n-1) \pi \lambda x /(2 l)]}{\cosh [(2 n-1) \pi \lambda t /(2 l)]} \sin \left[\frac{(2 n-1) \pi y}{2 l}\right] .
\end{aligned}
$$


The compatibility condition for the strain is not satisfied because of the assumption of Eqs. (3) and (5). Therefore, the proposed stress distribution is analytical solution, but they are not exact solution.

\subsection{Formulation of Energy Release Rate Using the RSF}

\section{Mod e l}

Here, only transverse cracking in $90^{\circ}$ ply under uniaxial tension is considered. The energy release rate associated with transverse cracking in $90^{\circ}$ ply is formulated using the RSF model. Considering that new transverse cracking propagates between two pre-existing transverse cracks (Fig.2), the energy release rate $G$ associated with transverse cracking is defined as

$$
G=\frac{U(l)-\left[U\left(l_{1}\right)+U\left(l_{2}\right)\right]}{2 t}
$$

where $U(l)$ is a strain energy stored in the RVE of crack spacing $2 l$ (Fig. 1 (b)). The strain energy $U(l)$ is expressed as

$$
U(l)=\frac{1}{2} \int_{V}\left(\sigma_{x} \varepsilon_{x}+\sigma_{y} \varepsilon_{y}+\sigma_{x y} \gamma_{x y}\right) d V,
$$

where the integration area $V$ is defined as the inside of the RVE (Fig. 1 (b)). Using Eqs. (1)-(3) and (18)-(20), Eq. (24) can be described as 


$$
\begin{gathered}
U(l)=\int_{0}^{t}\left\{\int _ { 0 } ^ { l } \left(A\{f(x, y)\}^{2}\left(\varepsilon_{y}^{p}+\varepsilon_{t h}\right)^{2}+B\{g(x, y)\}^{2}\left(\varepsilon_{y}^{p}+\varepsilon_{t h}\right)^{2}\right.\right. \\
\left.\left.+C f(x, y)\left(\varepsilon_{y}^{p}+\varepsilon_{t h}\right)\right) d y\right\} d x
\end{gathered}
$$

The constants $A, B$, and $C$ are calculated as

$$
\begin{gathered}
A=\frac{32}{\pi^{2}} \frac{\left(1+a^{2}\right) C_{1}+2 a C_{2}}{C_{1}^{2}-C_{2}^{2}}, \\
B=\frac{32}{\pi^{2}} G_{23} \lambda^{2}, \\
C=\frac{8}{\pi} \alpha_{2} \Delta T \frac{1+a}{C_{1}-C_{2}} .
\end{gathered}
$$

Substituting Eqs. (25)-(28) into Eq. (23), the energy release rate $G$ can be calculated using the RSF model. Equation (25) is calculated numerically using Gauss-Legendre quadrature because it is difficult to solve this equation analytically.

\subsection{Formulation of Energy Release Rate Using the CDM}

\section{Mod el}

For comparison with the energy release rate using RSF model, the energy release rate based on the CDM model is also formulated. In the CDM model, strain energy $U(l)$ stored in the RVE of crack spacing $2 l$ (Fig. 1 (b)) is expressed as

$$
U(l)=\frac{1}{2} \cdot E_{2}\left(1-d_{2}(l)\right)\left(\varepsilon_{y}^{p}\right)^{2} \cdot 4 t l,
$$

where $d_{2}(l)$ is the damage variable in the 2 -axis (direction normal to the fiber) as shown in Fig. 1 (a). According to 
Okabe et al. ${ }^{11)}$, by applying the Gudmundson-Zang $\operatorname{mode} 1^{7}$ ) the damage variable $d_{2}(l)$ is defined as

$$
d_{2}(l)=\frac{\pi}{2} \frac{t E_{1}\left(1-v_{12} v_{21}\right)}{E_{1}-E_{2} v_{12}^{2}} \frac{1}{l} \sum_{j=1}^{10} \frac{a_{j}}{(1+t / l)^{j}}
$$

where the constant sequence $a_{j}$ is given in Table 1 . Substituting Eqs. (29) and (30) into (23), the energy release rate $G$ can be calculated using the CDM model.

\section{ANALYSIS OF THE TRANSVERSE CRACKING} PROGRESSION USING THE MONTECARLO METHOD

Transverse cracking progression based on both stress and energy criteria was predicted using the Monte Carlo method. First, the $90^{\circ}$ ply of length $L$ is discretized into $n$ elements (Fig. 3 ). The static transverse strength of each element ply is affected by local defects. It is assumed that transverse strength $F_{i}$ of element $i(i=1,2, \ldots, n)$ follows Weibull distribution $R_{i}$, which reflects the random material property to resist crack formation:

$$
R_{i}=1-e^{-\frac{\Delta L}{L_{0}}\left(\frac{F_{i}}{\sigma_{0}}\right)^{m}}
$$

where $L_{0}$ is the gauge length, $\Delta L$ is the element spacing, $\sigma_{0}$ is the transverse strength of ply, and $m$ is the shape parameter. $R_{i}$ is determined by assigning pseudo-random numbers to each element, and the strength $F_{i}$ of each element is calculated using Eq. (31). The pseudo-random 
numbers are generated by Mathematica 9.0.30) Shape parameter $m$ is a fitting parameter in this study. Next, it is assumed that a micro crack occurat the ply strain $\varepsilon_{y}^{p}$ in each element satisfying the following stress criteria

$$
\sigma_{y}(0, y)>F_{i}
$$

where $\sigma_{y}(0, y)$ is stress in the $y$-direction at $x=0$ for the RSF model, given by Eq. (19).

It is then assumed that one of the micro cracks that occurred at the ply strain $\varepsilon_{y}^{p}$ propagates into a transverse crack. The element with the highest energy release rate associated with transverse cracking among the elements with microcracks is searched. When this element satisfies the energy criterion

$$
G>G_{C}
$$

the microcrack in this element propagates into a transverse crack. Here, $G_{c}$ is the critical energy release rate. Energy release rate $G$ is calculated using the expression formulated by the RSF model or the CDM model. The energy release rate $G$ is calculated assuming that there are virtual transverse cracks at either end of the $90^{\circ}$ ply of 1 ength $L$ The transverse crack density is calculated by dividing the number of transverse cracks with the exception of the virtual transverse cracks by the length $L$.

The progression of transverse cracking in laminates 
including $90^{\circ}$ plies is analyzed according to the stress and energy criteria. Figure 4 presents the analysis flowchart.

\section{RESULTS AND DISCUSSION}

\subsection{Crack-Initiated Laminate Stress}

Before predicting transverse cracking progression, the crack-initiated laminate stress is obtained using the formulated mechanical model and making a comparison with the experimental and analytical results obtained by Pagano ${ }^{1)}$ et al. The laminate material is IM7/5250-4. Table 1 lists its properties. The out-of-plane shear modulus $G_{23}$ is estimated using the following expression

$$
G_{23}=\frac{E_{2}}{2\left(1+v_{23}\right)} \text {. }
$$

Cross-ply $\left[0 / 90_{n} / 0\right](n=1,2,3,4)$ laminates with transverse cracks in the $90^{\circ}$ plies are considered. In this analysis, it is assumed that the cracks are equally spaced $\left(l_{1}=l_{2}=l / 2\right)$, and transverse crack density is defined as $\rho=$ 1/l. The crack-initiated laminate stress is determined using the following procedure.

(1) The energy release rate $G$ is calculated as a function of transverse crack density $\rho$ at ply strain $\varepsilon_{y}^{p}$ using the RSF model or the CDM model. The transverse crack density $\rho_{c}$ and ply strain $\left(\varepsilon_{y}^{p}\right)_{c}$ are evaluated when the 
maximum value of the energy release rate is equal to the critical energy release rate $G_{c}$.

(2) The effective compliance $\overline{\boldsymbol{C}}$ of the laminate at crack density $\rho_{c}$ is obtained from the model to predict the stiffness reduction of laminates including transverse cracks, formulated by Okabe et al., 11) and the stress $\sigma_{c}$ loaded in the laminate along the $0^{\circ}$ direction at $\left(\varepsilon_{y}^{p}\right)_{c}$ is obtained using the constitutive law. Stress $\sigma_{c}$ is defined as crack-initiated laminate stress.

Figure 5 plots the relationship between the crackinitiated laminate stress $\sigma_{c}$ calculated using the above method and the thickness of $90^{\circ}$ plies. Figure 5 also presents the experiment and analytical results obtained by Pagano ${ }^{1)}$ when the transverse crack penetrated the width direction of the specimen. The crack-initiated laminate stress obtained using the RSF model is the largest in the analytical models. The reason is that change in the strain distribution at the interfaces of ply with transverse cracks due to the occurrence of transverse cracks in the RSF model is not considered because the strain at the interfaces of the ply with transverse cracks defined by Eq. (16) is constant. Comparison of the RSF model with the experiment results indicates that the thicker the $90^{\circ}$ plies, the closer these 
values are. The crack-initiated laminate stress obtained using the CDM model is the smallest in the analytical models. It can be confirmed that the RSF model gives the upper limit of crack-initiated laminate stress, and the CDM model gives the lower limit.

\subsection{Prediction of Transverse Cracking Progression}

Transverse cracking progression is predicted using the mechanical model formulated in section 2 and the analysis method described in section 3, and compared with the experiment results of Ogihara et al. ${ }^{10)}$ The cross-ply laminates of $\mathrm{T} 800 \mathrm{H} / 3900-2$ and G40-800/5260 are analyzed. The material properties of T $800 \mathrm{H} / 3900-2$ and G40-800/5260 used in the calculation are listed in Table 3. The out-ofplane shear modulus $G_{23}$ is estimated using Eq. (34). The shape parameter $m$ is determined by fitting the relationship between transverse crack density and ply strain for the $[0 / 90]_{\text {s }}$ laminates obtained by Ogihara et al. ${ }^{10)}$ and the prediction result for the $[0 / 90]$ s laminates obtained using the RSF model. The length $L$ of the analysis region is $50 \mathrm{~mm}$, and there are 8000 elements $n$. The element spacing $\Delta L$ is calculated by dividing the length $L$ by the number of element $n$, and $\Delta L$ is $6.25 \times 10^{-3} \mathrm{~mm}$. Transverse crack density is calculated by dividing the number of transverse 
cracks by the length $L$.

First, the analysis results for the [0/90]s T800H/3900-2 laminate are considered. Figure 6 presents the transverse crack distribution in the $90^{\circ}$ ply for the $[0 / 90]$ s T800H/3900-2 laminate along the longitudinal length $L$ using the RSF model under $\varepsilon_{y}^{p}=1.08 \%$ or $\varepsilon_{y}^{p}=1.2 \%$. In Fig. 6 (a), there are 24 micro cracks and 12 transverse cracks. In Fig. 6 (b), there are 33 micro cracks and 28 transverse cracks. The transverse cracks are not equally spaced, and it is confirmed that the transverse cracks are distributed almost evenly as the ply strain increases. Figure 7 plots the relationship between the transverse crack density in the $90^{\circ}$ plies and the ply strain calculated using the Monte Carlo method described in section 3. For comparison, the experiment results of Ogihara et al. ${ }^{10)}$ are presented. The results obtained by the RSF model and the CDM model are in good agreement with the experimental results. The first cracking strain obtained using the RSF model exceeds that obtained using the CDM model. This result is consistent with the result in Fig. 7. The behavior of the RSF model and that of the CDM model are almost identical where the transverse crack density is high. Transverse crack density is defined as $\rho=1 / l$ assuming the cracks are equally spaced $\left(l_{1}=l_{2}=l / 2\right)$. The relationship between energy release rate $G$ 
and transverse crack density $\rho$ at ply strain $\varepsilon_{y}^{p}=1.0 \%$ is plotted in Fig. 8. The vales of the energy release rate of the RSF model and the CDM model are almost identical when $\rho$ is large. Therefore, the behaviors of the RSF model and the CDM model indicated in Fig. 7 almost agree when the transverse crack density is high.

Next, the analysis results for the G40-800/5260 laminate are presented. Figures 9 and 10 plot the relationship between transverse crack density and ply strain calculated using the Monte Carlo method for the [0/90]s and [0/902 s laminates. For comparison, the experiment results of Ogihara et al. ${ }^{10)}$ are presented in Figs. 9 and 10 . As in Fig. 7, the RSF model and the CDM model behaviors are almost identical in the range where transverse crack density is high. In Fig. 9, the RSF model gives the upper limit of crack-initiated laminate stress, and the CDM model gives the lower limit. The experiment results of the crackinitiated laminate stress exceed the values of the RSF model and the CDM model in Fig. 10. However, the results obtained using the RSF model and the CDM model agree well with the experiment results, regardless of the thickness of the $90^{\circ}$ plies, confirming the validity of this analysis. Furthermore, when comparing Figs. 9 and 10 , the results of the first cracking strain obtained using the RSF 
model become closer to the experiment values as the $90^{\circ}$ plies become thicker. This is consistent with the result in Fig. 5 .

This study calculates the results for cross-ply laminates. However, the presented models can be applied to an arbitrary laminate including $90^{\circ}$ plies. Furthermore, by combining the present model and the model for predicting stiffness reduction of laminates including transverse cracks formulated by Okabe et al. ${ }^{11)}$, it is possible to predict the stress-strain behavior of the laminate.

\section{CONCLUSIONS}

This study investigated transverse cracking progression in laminates including $90^{\circ}$ plies. The RSF model, which takes into account the thermal residual strain for ply including transverse cracks, is formulated, and the energy release rate associated with transverse cracking is calculated using this model. For comparison, the energy release rate based on the CDM model is formulated. Next, transverse cracking progression in CFRP cross-ply laminates including $90^{\circ}$ plies based on both stress and energy criteria is predicted using the Monte Carlo method. The results indicated that the RSF model and CDM model proposed in this study can predict the experiment results 
for the relationship between transverse crack density and ply strain in $90^{\circ}$ ply obtained by Ogihara et al. ${ }^{10)}$ In this study, the results for cross-ply laminates are calculated; however, the presented models can be applied to an arbitrary laminate including $90^{\circ} \mathrm{ply}$.

\section{A C KN OWLED GE MENTS}

T. O. appreciates the support of the Cross-ministerial Strategic Innovation Promotion Program and the Ministry of Education, Cluture, Sports, Science and Technology of Japan under Grant-in-Aid Scientific Research (C) No. 15K06597. This work was partly supported by Toray Industries, Inc. and the New Energy and Industrial Technology Development Organization (NEDO) No. $15102315-0$, P 15006 , and $141001611-d$.

\section{R E F E R E N C E S}

1) N.J. Pagano, G.A. Schoeppner \& R. Kim : Comp. Sci. Tech., 58,11(1998), $1811-1825$.

2) A. S. D. Wang, P. C. Chou \& S.C. Lei : J. Comp. Mater., 18,3 (1984), 239-254.

3) J.M. Berthelot \& J. -F. Le Corre: Comp. Sci.Tech., 60, $14(20000), 2659-2669$.

4) J.M. Berthelot, Appl. Mech.Rev., 56,1 (2003), 111-147. 
5) J.M. Berthelot, P. Leblond, A. El Mahi \& J. -F. Le Corre : Comp.PartA, 27, 10 (1996), 989-1001.

6) N. Takeda, \& S. Ogihara : Comp. Sci.Tech., 52, 2 (1994), $183-195$.

7) P. Gudmundson \& W. Zang: Int. J. Solid Structures, 30, $23(1993), 3211-3231$.

8) S. Kobayashi, S. Ogihara, \& N. Takeda: Adv. Comp. Mater., 9, $4(2000), 363-375$.

9) S. Kobayashi, S. Ogihara \& N. Takeda: Adv. Comp. Mater.,9,3 (2000), 241-251.

10) S. Ogihara, S. Kobayashi, N. Takeda, A. Kobayashi: Comp. Sci. Tech., 61,8(2001), 1049-1055.

11) T. Okabe, S. Onodera, Y. Kumagai \& Y. Nagumo : Int. J. Damage mech. (in press).

12) G. J. Dvorak, N. Laws \& M. Hejazi: J. Comp. Mater., $19,3(1985), 216-234$.

13 ) G. J. Dvorak \& N.Laws : J. Comp. Mater., 21, 4 (1987), $309-329$.

14) G. J. Dvorak \& N. Laws:Eng. Frac. Mech., 25, 5-6 $(1986), 763-770$.

$15)$ McCartney, L. N.: J. Mech. Phys. Solids, 40,1 (1992), $27-68$.

16) McCartney, L. N.: Stress transfer mechanics for ply cracks in general symmetric laminates, NPI, Report 
CMMT(A)50, National Physics Laboratory, Teddington, $\mathrm{UK}, 1996$.

17) J.A. Nairn: J. Comp. Mater., 23, 11 (1989), $1106-$ 1129.

$18) \quad$ J. A. Nairn \& S. Hu : Int. J.Fract., 57, 1 (1992), 1 24.

19) Y. Huang, J. Varna \& R. Talreja : Comp. Sci. Tech., 95, (2014), $100-106$.

$20)$ S. Ogihara, N. Takeda, S. Kobayashi \& A. Kobayashi :

J. Soc. Mat. Sci., Japan, 47, 1 (1998), 68-72.

21) N. Takeda, H. Niizuma, S. Ogihara \& A. Kobayashi : Materials system, Japan, 14, (1995), $73-78$.

22) E. V. Iarve, M.R. Gurvich, D.H. Mollenhauer, C.A. Rose \& C.G. Dávila: Int. J. Numer. Meth. Eng., 88, 8 (2011), $749-773$.

23 ) E.V. Iarve, S. Chellapilla \& D. H. Mollenhauer : ICCM 15 Conference Proceedings, Durbon, S. Africa June $27-\mathrm{July} 2,(20005)$.

$24)$ M. R. Gurvich : Comp. Sci. Tech., 59, 11 (1999), $1701-1711$.

$25)$ J. W. Lee, D. H. Allen and C. E. Harris: J. Comp. Mater., 23,12(1989), $1273-1291$.

26) S. Murakami : Continuum Damage Mechanics: A Continuum Mechanics Approach to the Analysis of 
Damage and Fracture. Dordrecht Heidelberg London New York: Springer, (2012).

27) Y. Kanagawa, S. Murakami, Y. Liu, Q. Bai \& K. Tanaka:J. Soc. Mat. Sci., Japan 45,2 (1996), 206-211. $28)$ Z.C.Xia, R.R. Carr \& J.W. Hutchinson: Acta Metall. Mater., 41,8 (1993),2365-2376.

29) Z. Hashin: Eng. Frac. Mech., 25, 5-6 (1986), 771 778.

30) Wolfram Research, Inc., Mathematica, Version 9.0, Champaign, IL ( 201012$)$.

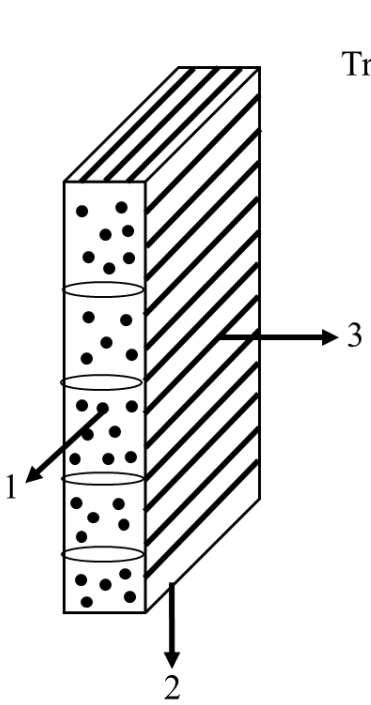

(a)

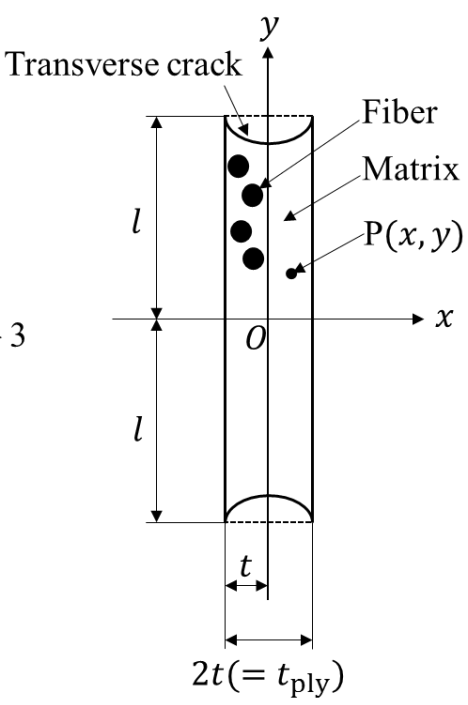

(b)

Fig. 1. Schematic of transverse crack model. (a) Ply including transverse crack. (b) Representative volume element. 


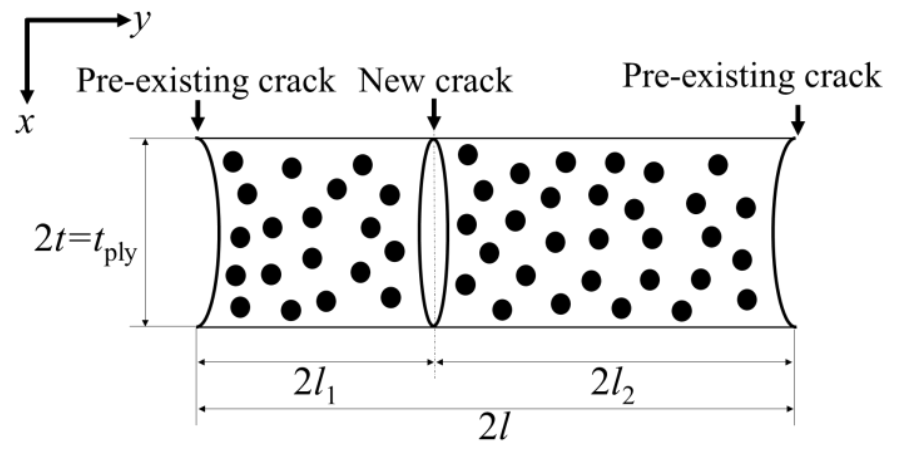

Fig. 2. Formation of a new crack between two preexisting cracks.

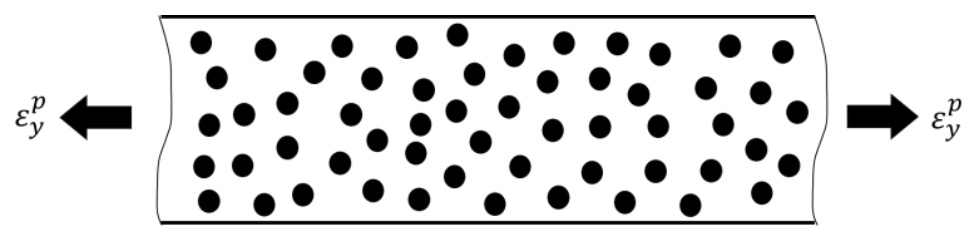

Discretize $90^{\circ}$ layer $\downarrow$

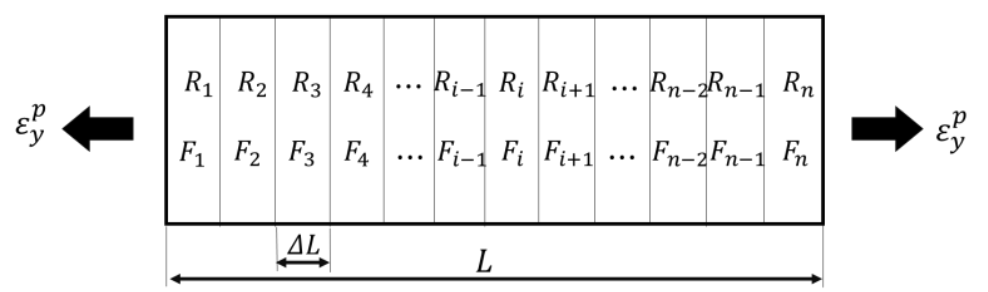

Fig. 3. Discretization of $90^{\circ}$ plies for distributed static transverse strength. 


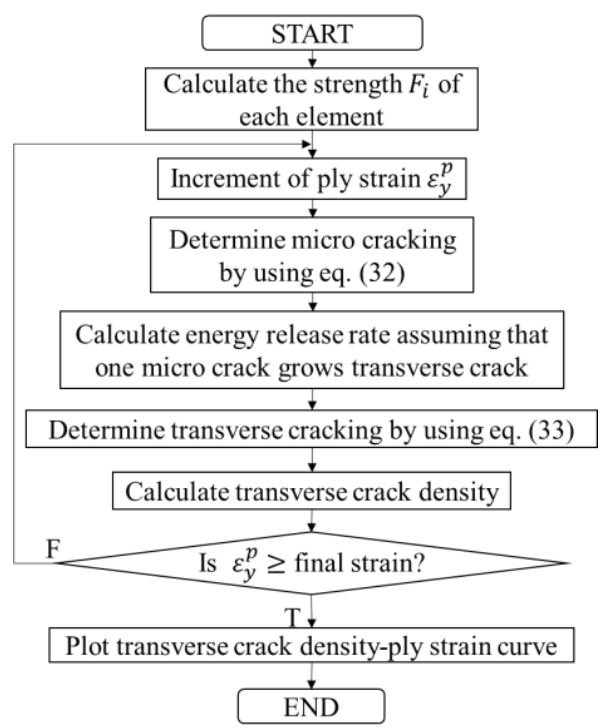

Fig. 4. Flow chart of the procedure implemented for analyzing the progress of transverse cracking.

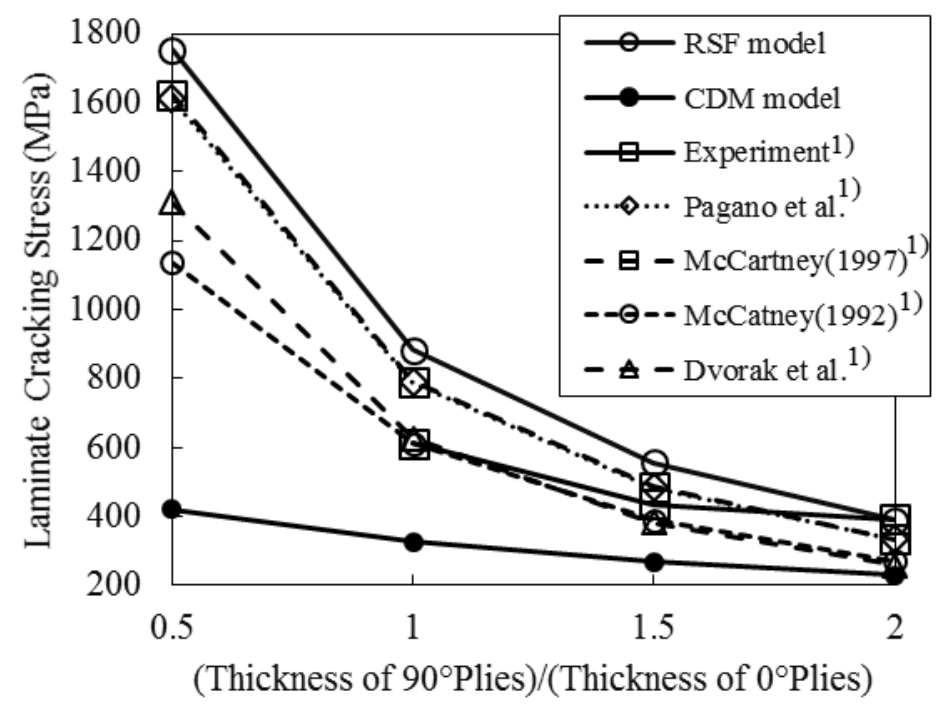

Fig. 5. Laminate cracking stress as a function of thickness of $90^{\circ}$ plies / thickness of $0^{\circ}$ plies. 


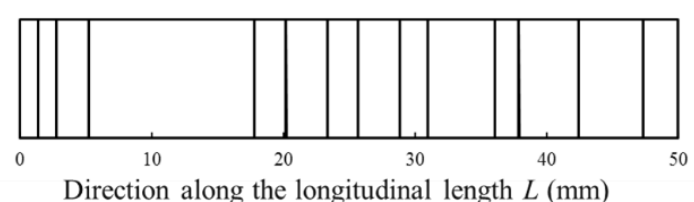

(a) $\varepsilon_{y}^{p}=1.08 \%$

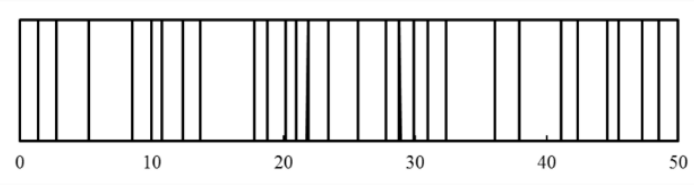

Direction along the longitudinal length $L(\mathrm{~mm})$

(b) $\varepsilon_{y}^{p}=1.2 \%$

Fig. 6. Prediction of transverse crack distribution in the $90^{\circ}$ ply for $[0 / 90]_{s} \mathrm{~T} 800 \mathrm{H} / 3900-2$ laminate along the longitudinal length $L$ using RSF model. Each vertical line represents one transverse crack. (a) Under $\varepsilon_{y}^{p}=1.08 \%$, (b) Under $\varepsilon_{y}^{p}=1.2 \%$.

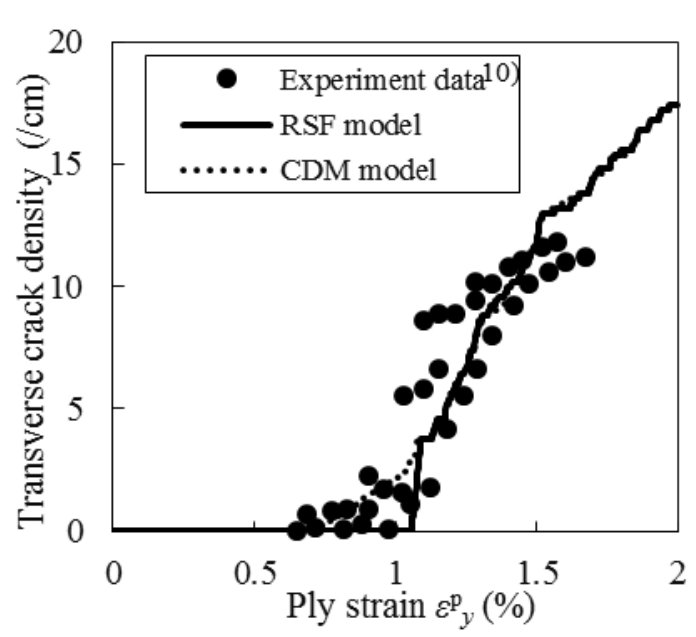

Fig. 7. Transverse crack density in the $90^{\circ} \mathrm{ply}$ for [0/90]s T800H/3900-2 laminate as a function of ply strain. 


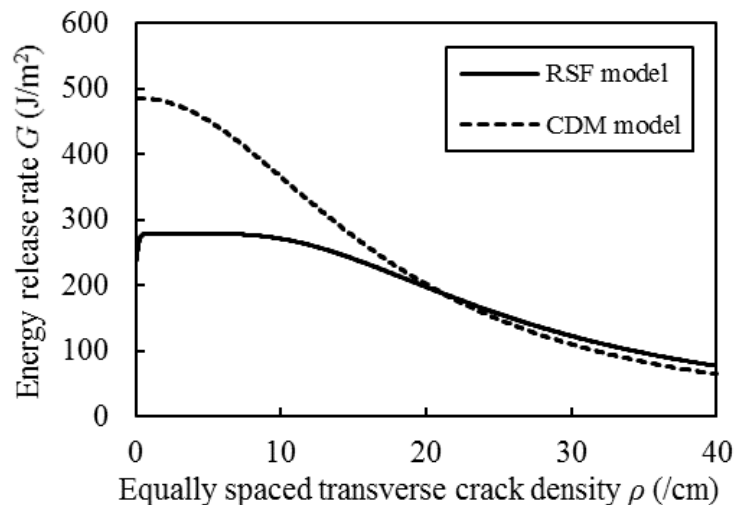

Fig. 8. Energy release rate associated with transverse cracking in $90^{\circ}$ ply as a function of equally spaced transverse crack density for [0/90]s T $800 \mathrm{H} / 3900-2$ laminate $\left(\varepsilon_{y}^{p}=1.0 \%\right)$

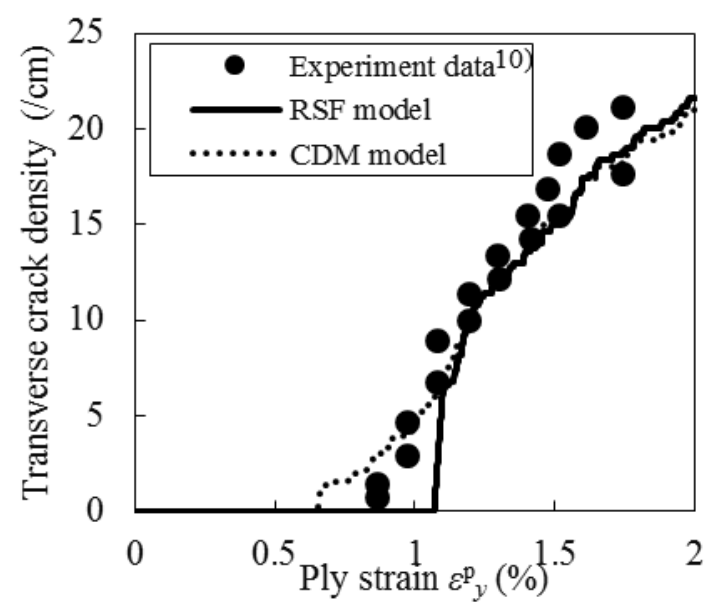

Fig. 9. Transverse crack density in $90^{\circ}$ ply for $[0 / 90]$ s G40-800/5260 laminate as a function of ply strain. 


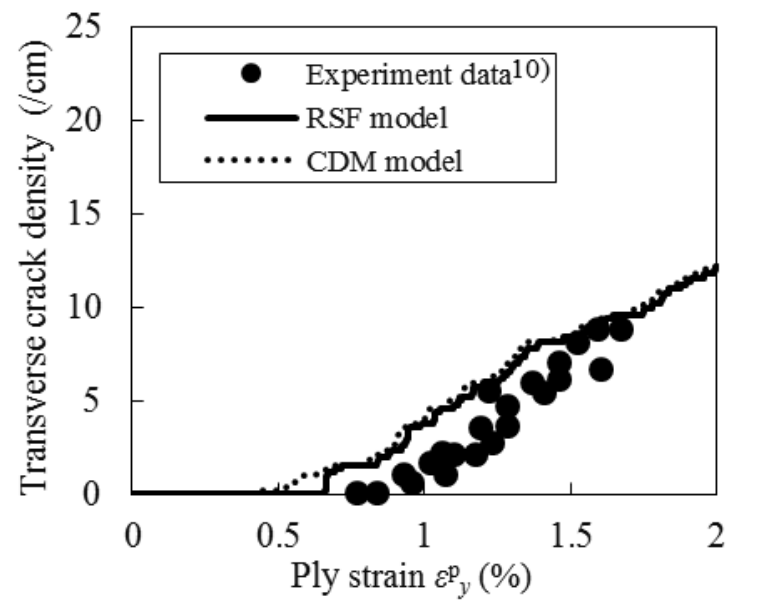

Fig. 10. Transuerse crack density in $90^{\circ}$ ply for [0/902 $]_{s}$ G $40-800 / 5260$ laminate as a function of ply strain. 
Table 1. Numerical parameter $a_{j}$ used in Eq. $(30)^{7)}$.

\begin{tabular}{c|c|c|c}
\hline$j$ & $a_{j}$ & $j$ & $a_{j}$ \\
\hline 1 & 0.63666 & 6 & -33.09444 \\
2 & 0.51806 & 7 & 74.32002 \\
3 & 0.51695 & 8 & -103.06411 \\
4 & -1.04897 & 9 & 73.60337 \\
5 & 8.95572 & 10 & -20.34326 \\
\hline
\end{tabular}


Table 2. Material properties of IM7/5250-4. ${ }^{1}$ )

Longitudinal Young's Modulus $E_{1}$ (GPa) 165.475

Transverse Young's Modulus $E_{2}$ (GPa) 10.342

\begin{tabular}{|c|c|}
\hline In-Plane Poisson's Ratio $v_{12}$ & 0.31 \\
\hline Out-of-Plane Poisson's Ratio $v_{23}$ & 0.56 \\
\hline In-Plane Shear Modulus $G_{12} \quad$ (GPa) & 5.7922 \\
\hline Longitudinal Thermal Expansion & 0.45 \\
\hline Coefficient $\alpha_{1}\left(10^{-6} /{ }^{\circ} \mathrm{C}\right)$ & \\
\hline Transverse Thermal Expansion & 24.66 \\
\hline Coefficient $\alpha_{2}\left(10^{-6} /{ }^{\circ} \mathrm{C}\right)$ & \\
\hline Stress-Free Temperature $T_{s f}\left({ }^{\circ} \mathrm{C}\right)$ & 180 \\
\hline
\end{tabular}

Ambient Testing Temperature $T\left({ }^{\circ} \mathrm{C}\right)$

Ply thickness $t_{0} \quad(\mathrm{~mm})$

0.127

Critical Energy Release Rate $G_{c}\left(\mathrm{~J} / \mathrm{m}^{2}\right)$

225 
Table 3. Material properties of T $800 \mathrm{H} / 3900-2$ and G40-

$$
800 / 5260 .^{8,9)}
$$

\begin{tabular}{|c|c|c|}
\hline & T $800 \mathrm{H} / 3900-2$ & G $40-800 / 5260$ \\
\hline Longitudinal Young's Modulus $E_{1}$ (GPa) & 143.0 & 152.0 \\
\hline Transverse Young's Modulus $E_{2}$ (GPa) & 7.99 & 10.0 \\
\hline In-Plane Poisson's Ratio $v_{12}$ & 0.35 & 0.33 \\
\hline Out-of-Plane Poisson's Ratio $v_{23}$ & 0.49 & 0.49 \\
\hline In-P1ane Shear Modulus $G_{12} \quad$ (GPa) & 3.96 & 6.94 \\
\hline \multicolumn{3}{|l|}{ Longitudinal Thermal Expansion } \\
\hline \multicolumn{3}{|l|}{ Coefficient $\alpha_{1}\left(10^{-6} /{ }^{\circ} \mathrm{C}\right)$} \\
\hline \multicolumn{3}{|l|}{ Transverse Thermal Expansion } \\
\hline \multicolumn{3}{|l|}{ Coefficient $\alpha_{2}\left(10^{-6} /{ }^{\circ} \mathrm{C}\right)$} \\
\hline Stress-Free Temperature $T_{s f}\left({ }^{\circ} \mathrm{C}\right)$ & 165 & 195 \\
\hline Ambient Testing Temperature $T\left({ }^{\circ} \mathrm{C}\right)$ & 25 & 25 \\
\hline Ply thickness $t_{\text {ply }}(\mathrm{mm})$ & 0.18 & 0.14 \\
\hline Gauge length $L_{0} \quad(\mathrm{~mm})$ & 80 & 80 \\
\hline Critical Average Stress $\sigma_{0}$ (MPa) & 72 & 75 \\
\hline Distribution Shape Constant $m$ & 10.5 & 7.5 \\
\hline Critical Energy Release Rate $G_{c}\left(\mathrm{~J} / \mathrm{m}^{2}\right)$ & 300 & 330 \\
\hline
\end{tabular}

